\title{
Hipertexto sobre História da Ciência: recurso auxiliar para aulas de Física
}

\author{
Hypertext on Science History: auxiliary resource for Physical classes
}

\author{
Daiane Carla Casonatto', Ana Marli Bulegon"
}

\section{Resumo}

O presente artigo, relata parte da pesquisa desenvolvida pelas autoras no âmbito do curso de Mestrado Profissional em Ensino de Física, no ano de 2015. Apresenta uma análise do uso do Hipertexto, inserido no Moodle, enquanto Ambiente Virtual de Aprendizagem (AVA), como um recurso auxiliar para as aulas de Física. O objetivo deste trabalho, foi verificar as contribuições do Hipertexto, para o Ensino de Física na abordagem do tema História da Ciência (HC). Participaram da pesquisa os discentes do sétimo período do curso de Física Licenciatura Plena, modalidade Parfor, de uma instituição de ensino na cidade de Chapecó/SC. No hipertexto fez-se uso de links para acesso a vídeos, simulações, textos, entre outros e o mesmo foi disponibilizado aos participantes no Moodle. Como resultado foi possível verificar a motivação dos participantes em buscar mais conhecimentos sobre o tema HC, além de aprender formas diferenciadas de utilização das Tecnologias de Informação e Comunicação (TIC) no Ensino de Física.

Palavras-chave: Ensino de Física, Moodle, Ambiente Virtual de Aprendizagem.

\section{Abstract}

This article reports a part of the research developed by the author in her dissertation, presented to the Professional Master's Degree in Physics Teaching, in the year 2015. It presents an analysis of the use of Hypertext, inserted in Moodle, as Virtual Learning Environment (AVA). As an auxiliary resource for physics classes. The objective of this work was to verify the contributions of Hypertext, for Teaching Physics in the approach to the theme History of Science (HC). Participants of the study were the seventh-year students of the Physics Undergraduate Full Degree, Parfor modality, from a teaching institution in the city of Chapecó/SC. In the hypertext, links were used to access videos, simulations, texts, among others and the same was made available to participants in Moodle. As a final result, it was possible to verify the motivation of the participants to seek more knowledge about the theme of History of Science besides learning ways of using ICT in Teaching Physics.

Keywords: Physics Teaching, Moodle, Virtual Learning Environment. 


\section{Introdução}

Com a expansão rápida e de fácil acesso aos meios de comunicação ou tecnológicos, verifica-se a ampliação de recursos pedagógicos oriundos das Tecnologias da Informação e Comunicação (TIC). Esses recursos podem ser utilizados tanto para o professor como para o aluno no processo de ensino e aprendizagem, o que favorece o protagonismo de ambos. Segundo Tornaghi (2005) as tecnologias digitais condicionam e criam novas condições para a produção escolar. Estas, proporcionam aos professores realizar o ensino de conteúdos escolares de uma forma interativa e dinâmica, modificando, muitas vezes o modo como o professor trabalha em sala de aula.

Nas Ciências em geral, e na Física em particular, verifica-se a abstração de alguns conceitos de difícil compreensão para os estudantes e que podem ser explicitados com o uso da TIC em sala de aula ou fora dela. Isso contribui para que a Física possa ser melhor compreendida e seu estudo tornar-se atraente para os estudantes.

No Ensino de Física, estudar a História das Ciências (HC), é viajar por diversos cantos do mundo, conhecer diferentes povos e culturas, permitir que tenhamos uma visão mais concreta da natureza real da ciência, seus métodos e suas limitações. É também, estabelecer condições para relacionar conhecimentos que temos hoje sobre o mundo físico, os quais resultaram de um longo processo histórico de várias experiências e formulações de teorias, erros e acertos, que nos mostram o caminho pelo qual a Física andou em direção ao desenvolvimento. Dessa maneira, mesmo ainda não sendo muito utilizada como tema de ensino, a HC apresenta-se como uma estratégia pela qual é possível a aproximação dos aspectos científicos dos acontecimentos históricos, possibilitando ampliar a visão de construção humana e desenvolvimento e as consequências para a sociedade e a necessidade de compreendê-las para sobreviver.

Dessa forma, este trabalho apresenta a análise do uso do Hipertexto, elaborado com o tema $\mathrm{HC}$ por meio de atividades de aprendizagem com links para vídeos, animações, simulações, entre outros. O hipertexto foi disponibilizado para os estudantes no Moodle, enquanto Ambiente Virtual de Aprendizagem (AVA), e faz parte de um trabalho maior que foi o de investigar as contribuições das TIC no processo de aprendizagem de HC (dissertação de mestrado de uma das autoras).

Para o desenvolvimento desses objetivos foi realizado um estudo de caso que envolveu estudantes do sétimo período do curso de Física Licenciatura Plena de uma instituição de ensino superior (IES) na cidade de Chapecó/SC. A coleta de dados fez uso de questionário e observações. O texto a seguir apresenta o embasamento teórico da presente pesquisa, a metodologia utilizada na obtenção dos dados, os resultados e considerações deste estudo.

\section{A Influência das Tecnologias no Contexto Escolar}

Modificar ou substituir uma aula de Física, que faz uso de quadro e giz, por uma aula com uso de TIC, pode agregar e modificar a qualidade no processo de ensino e aprendizagem dos conceitos estudados nela. Bulegon (2011) e Gomes (2000, apud MENEZES, 2009, p.81) destacam a relevância do uso das TIC no processo de construção do conhecimento - principalmente, na produção e utilização das informações no contexto da educação formal -, por facilitar a interação entre os sujeitos inseridos nos ambientes da cultura. De acordo com Menezes (2009, p.50) “[...] as TIC estão se convertendo cada vez mais em parte integrante de nossas vidas, tanto no aspecto do mundo do trabalho como em nossa vida diária."

Para Gomes (2000, apud MENEZES, 2009) com o apoio dos recursos tecnológicos, o homem recria seus espaços culturais, amplia o acervo de conhecimentos e suas formas de circulação, como também explora novas possibilidades de apreensão e ressignificação do mundo, transformando a aquisição do conhecimento em um processo dinâmico e complexo. Além disso, para esses autores o uso das TIC

No que diz respeito ao acesso ao conhecimento, seu uso é essencial para a integração do jovem no mundo do trabalho e garantia de uma cidadania ativa. As TIC são um instrumento para uma aprendizagem eficiente e flexível, pois oferecem soluções individuais e flexíveis para cada tipo de problema, seja ele a distância, o tempo e o lugar, desde que se tenha uma estratégia pedagógica bem definida. (GOMES, 2000 apud MENEZES, 2009, p.81)

Para Medeiros e Medeiros (2002), o professor ao utilizar os recursos das TIC, deverá interagir com os estudantes, para que ocorra o envolvimento cognitivo em um nível profundo, contribuindo com a busca de soluções aos inúmeros desafios encontrados e enfrentados para a melhoria na execução e no planejamento de suas aulas.

Dentre os recursos das TIC possíveis para usar no ensino o hipertexto é uma opção que congrega diversas mídias e por isso pode contribuir para tornar a aprendizagem mais eficiente.

\subsection{O Hipertexto: Características e Definições}

De acordo com Levy (1993), um Hipertexto

[...] é um conjunto de nós ligados por conexões. Os nós podem ser palavras, páginas, gráficos, sequências sonoras, documentos complexos que podem eles mesmos ser hipertextos. Os itens de informação não são ligados linearmente, como uma corda com nós, mas caba um deles, ou a maioria, estende suas conexões em estrela, de modo reticular. (LÉVY, 1993, p.36).

Este formato textual, que agrega diversas mídias, vem 
criando novas perspectivas de ensino e de aprendizagem, “o que gera uma ampliação na memória, imaginação, percepção e raciocínio, aumentando o potencial de inteligência coletiva na humanidade”. (DESSBESELL e FRUET, 2012, p. 43). Diante disso,

Torna-se indispensável destacar que com o avanço das tecnologias o contexto de produção de leitura e escrita passou por mudanças significativas, o hipertexto passa a constituir o leitor também como autor, no momento que lhe permite interagir com o texto e fazer suas escolhas. Porém o leitor precisa saber fazer uso desses recursos, o que lhe exigirá certa cautela no momento em que se deparará com um universo de informações trazido até ele por meio da internet. (DESSBESELL e FRUET, 2012, p.45)

Segundo Boettcher (2009) o hipertexto permite ao leitor formas variadas de leitura, uso, manuseio e uma pluralidade de possibilidades de interação, por ser uma rede multidimensional com nós e links que possibilita uma leitura descontínua. Deste modo verifica-se que o hipertexto torna a leitura dinâmica, pois um simples click do leitor, em links, o leva para novos textos, implicando em descobertas, escolhas, pistas, associação e seleção de informações, uma busca de opiniões e caminhos.

Para Dessbesell e Fruet (2012, p. 44), o hipertexto se diferencia do texto impresso em aspectos relativos à ruptura conectividade máxima entre blocos de significado e multicentramento, um texto aberto, comunicativo, a partir das realizações do percurso do leitor, enquanto o texto impresso é constituído numa lógica de começo, meio e fim definidos pelo leitor, o hipertexto sem começo e fim previamente determinados pelo autor, é o leitor quem constrói alternativas de leitura.

\subsection{O Hipertexto e a Educação}

A construção de hipertextos, de acordo com a definição de Levy (1993) não é nova na Educação. Desde muito tempo as crianças são estimuladas a fazer cartazes com técnicas de recorte e cole em cartolina. Entretanto, com a chegada dos computadores e da internet surgiram softwares que facilitam sua construção e permitem incluir neles links de vídeos, áudios e textos. Os infográficos, na atualidade, ficaram mais interativos e modernos e podem ser utilizados em qualquer idade escolar.

De acordo com Bulegon, Drescher e Santos (2019), verifica-se algumas vantagens do uso do hipertexto na Educação como: potencializam a aprendizagem (por usar imagens e textos); favorecem a autonomia dos estudantes; estimulam a criatividade; podem ser utilizados como recursos para a construção do conhecimento e/ou instrumentos de avaliação da aprendizagem; entre outros.

\section{História da Ciência e o ensino de Ciências}

A Ciência encontra-se em muitos momentos históricos e em diversas civilizações (Figura 1). Ela surgiu pela necessidade de sobrevivência de explicar fatos e fenôme- nos do cotidiano, além de controlar e modificar o que a natureza tem a oferecer. Através disso é possível perceber os inúmeros avanços que aconteceram nesta ciência. A Física, por exemplo, é uma ciência fundamental para a construção da cidadania por estar incorporada à cultura e integrada na sociedade como instrumento tecnológico. É por meio dela que conseguimos compreender e explicar diversos fenômenos da natureza e do Universo. Estudar a História da Ciência (HC), portanto, é uma ferramenta necessária no processo de ensino e de aprendizagem.

Conhecer a evolução histórica dos conceitos é fundamental para a compreensão de como cada sociedade deixou suas marcas, maneiras e formas de saber e fazer Ciência. Nesse sentido, é fundamental que os professores estudem a HC para oferecer aos estudantes o desenvolvimento de valores e técnicas da área do conhecimento que ensinamos do modo como ele foi concebido, como sugerem os Parâmetros Curriculares Nacionais (PCN):

A Física percebida enquanto construção histórica, como atividade social humana, emerge da cultura e leva à compreensão de que modelos explicativos não são únicos nem finais, tendo se sucedido ao longo dos tempos, como o modelo geocêntrico, substituído pelo heliocêntrico, a teoria do calórico pelo conceito de calor como energia, ou a sucessão dos vários modelos explicativos para a luz. O surgimento de teorias físicas mantém uma relação complexa com o contexto social em que ocorreram (BRASIL, 2002, p.27).

Além disso, Oliveira e Silva (2012) argumentam que o ensino de Ciências, utilizando a HC, contribui para: humanizar o conteúdo ensinado; favorecer uma melhor compreensão dos conceitos científicos, na medida em que contextualiza e discute alguns aspectos não abordados nos livros didáticos, mas que são percebidos no cotidiano dos estudantes; ressaltar o valor cultural da ciência; enfatizar o caráter mutável do conhecimento científico; e, permite uma melhor compreensão do método científico. Esses aspectos são corroborados por Batista e Araman (2009, p. 476)

O uso da aplicação didática da História da Ciência vem sendo amplamente discutido, com pesquisas que implementem a utilização de materiais históricos de qualidade em sala de aula os quais poderão contribuir para: a) propiciar uma aprendizagem de Ciências mais significativa, aproveitando as concepções alternativas dos alunos; b) contribuir para a compreensão do aluno de que o pensamento científico evolui com o tempo, portanto as teorias científicas são fonte de constantes revisões; c) proporcionar uma metodologia diferenciada para o ensino de Ciências; d) relacionar o desenvolvimento científico com os avanços tecnológicos da sociedade, seus benefícios e seus problemas, contribuindo para a formação crítica do aluno.

Buscar conhecer a construção dos primeiros conceitos é, sem dúvida, gratificante e muito necessário para nós educadores, pois oferecer ao aluno a busca e o desenvolvimento histórico nos faz compreender que a ciência foi construída em um tempo e espaço determinado por 
Figura 1- Marcos na História da Ciência e os conceitos de Física

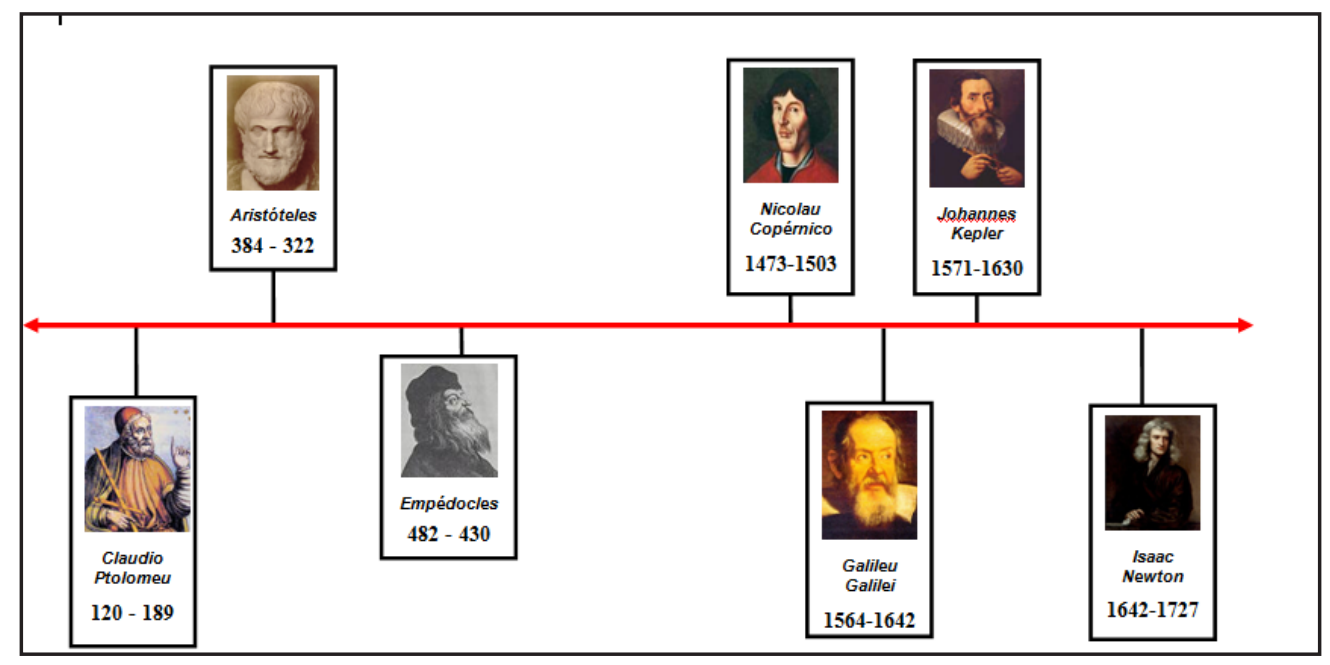

vários homens geniais e que apesar das dificuldades e dos conflitos encontrados em cada época, elaboraram uma complexidade sem limites na caminhada pela busca do conhecimento, para a formulação de suas teorias e a busca para a aceitação de suas descobertas que às vezes levavam anos para serem aceitas. Além disso, permite o desenvolvimento de valores e técnicas na área do conhecimento Físico, que desperte a atenção, o interesse e os faça compreender os processos que envolveram a produção daqueles conhecimentos. Desse modo, a inclusão da HC no ensino, deve caminhar para uma abordagem

Com construção racional, crítica, polêmica, investigadora do imaginário, [...] que desvende e revele não só o sucesso, mas os fracassos ocorridos ao longo de todo esse desenvolvimento da física, enfim, que apresente o caráter dinâmico que foi característica do passado, e que certamente, será mais dinâmico se trabalhado com uma educação inovadora. (NEVES, 2006, p. 25)

Este modo levará os alunos a perceberem que existe um caráter humano na construção científica, que os cientistas são "homens comuns, passíveis, que sofrem influências culturais, sociais e religiosas da época em que vivem além do caráter temporário das teorias e modelos, ao perceber que estas vão se modificando ao longo do tempo" (NEVES, 2006, p. 26). É possível ainda, através da história, compreender a formação cultural do mundo em que vivemos, as ideias do senso comum que ainda existem em nosso meio, compreender o que é ciência e não apenas seus resultados. Isto pode ser usado em uma aula de aspecto puramente técnico, como um complemento que destaca os aspectos sociais, políticos, humanos e culturais.

Entretanto, a dimensão investigativa do desenvolvimento da ciência, a qual poderia ser dada especial atenção na escola, através do envolvimento de sua história nas aulas, não consta da abordagem dos livros didáticos e, consequentemente, não é trabalhada pelos professores. Tal aspecto insinua aos alunos que as teorias surgem definitivas, e que não são resultados de longos anos, décadas e até mesmo séculos de estudos e investigações. Tal procedimento, para a apresentação da HC nos livros didáticos, é um instrumento inviável para a apresentação aos estudantes, a pouca presença ou a presença distorcida dos assuntos que são encontrados, promovem apenas. Nesse sentido, Castro e Carvalho (1992, p.227) afirmam que

Encarar a ciência como um produto acabado confere ao conhecimento científico uma falsa simplicidade que se revela cada vez mais como uma barreira a qualquer construção, uma vez que contribui para a formação de uma atitude ingênua frente à ciência.

Ao utilizar a HC no Ensino da Física é possível "dar vida, dinâmica, integridade, criticidade e inquietação aos conteúdos escolares, desenvolvendo também habilidades e atitudes que caracterizem o aluno como um sujeito em ação, construtor do seu processo histórico" (SLONGO, 1998, p.63).

Para os alunos, servirá como sugestões para novas interpretações de conceitos que parecem ser fixos, além de perceberem que as dúvidas que possuem sobre determinados conteúdos e conceitos são perfeitamente cabíveis comparando-as com o tempo e o processo lento para pleno desenvolvimento, até chegar às concepções aceitas atualmente. Isso pode ocorrer desde que esta história seja trabalhada com materiais históricos apropriados e de boa qualidade. Pois não se pode "alimentar expectativas que a história junto ao ensino será a solução dos problemas da didática da Física" (PIETROCOLA, 2005, p. 157). Destacamos a afirmação de Slongo (1998, p.69):

O que se pretende com a utilização da História da Ciência no ensino, não é que o aluno reconstitua todos os passos percorridos até hoje na elaboração do conhecimento. O que estou propondo é a utilização da História da Ciência na problematização do conhecimento, na identificação dos mecanismos que conduziram à sua produção, na sua relação com o contexto no qual o aluno acha-se inserido, buscando melhor compreendê-lo, instrumentalizando o aluno para atuar na perspectiva das transformações. 
Trabalhar a HC requer uma construção de estratégias concretas de ação em sala de aula, que faça com que os alunos levem a sério, que pesquisem, leiam e reflitam sobre os assuntos e não somente apresentar informações prontas, pois de acordo com Guerra, Reis e Braga (2002) transformar as aulas de Física somente em HC seria restrito e tornaria as aulas empobrecedoras.

\section{Aspectos metodológicos}

A pesquisa aqui relatada é do tipo exploratória, pois de acordo com Gil (1999) ela possui a finalidade "[...] de desenvolver, esclarecer e modificar conceitos e ideias para a formulação de abordagens posteriores” (p. 46). Caracterizou-se como qualitativa, pois segundo Minayo (1993) a abordagem qualitativa preocupa-se com um nível de realidade que não pode ser quantificado e trabalha com significados, motivos, aspirações, crenças valores e atitudes.

Trata-se de um estudo de caso, desenvolvido com os discentes (em número de 11, com idade entre 24 e 52 anos) de uma turma do curso de Física Licenciatura Plena, modalidade Parfor, de uma instituição de ensino superior (IES), na cidade de Chapecó/SC para estudar o tema: História da Ciência.

Para apoiar esse estudo foi elaborado um hipertexto sobre o tema: História da Ciência ${ }^{1}$ e disponibilizado no Moodle para posterior diálogo e socialização em espaços extraclasse. O estudo foi realizado em quatro encontros, sendo três presenciais e um a distância. Os instrumentos de coleta de dados constituíram-se de questionários.

\subsection{Atividades Desenvolvidas}

O hipertexto foi organizado de acordo com a metodologia dos três momentos pedagógicos (TMP), apresentada por Delizoicov, Angotti e Pernambuco (2002) - Problematização inicial (PI), Organização do conhecimento (OC) e Aplicação do conhecimento (AC). O hipertexto pontuou, basicamente, algumas biografias de cientistas e descobertas da Ciência e utilizou recursos didáticos como: atividades experimentais e lúdicas, questionário, textos, links de vídeos, entre outros. Para promover a reflexão e socialização dos conhecimentos desenvolvidos nos encontros presenciais com uso do hipertexto, fez-se uso de fóruns de discussão no Moodle. A Figura 2 - Descobertas da Ciência, mostra a tela do hipertexto que aborda algumas descobertas científicas que estudamos atualmente.

O usuário do hipertexto pode clicar sobre cada imagem e este o levará a uma síntese sobre a descoberta da ciência estudada nos Livros didáticos, aprovados pelo Programa Nacional do Livro Didático (PNLD), além de atividades experimentais, vídeos e simulações sobre o tema.

Na última imagem, por exemplo, o tema Relatividade Geral e Restrita apresenta diversas possibilidades de discussão sobre esse tema (Figura 03). Os recursos

Produto Educacional - https://www.ufn.edu.br/site/ensino/ mestrado/programa-de-posgraduacao-em-ensino-de-ciencias-ematematica/producoes/
Figura 2 - Descobertas da ciência

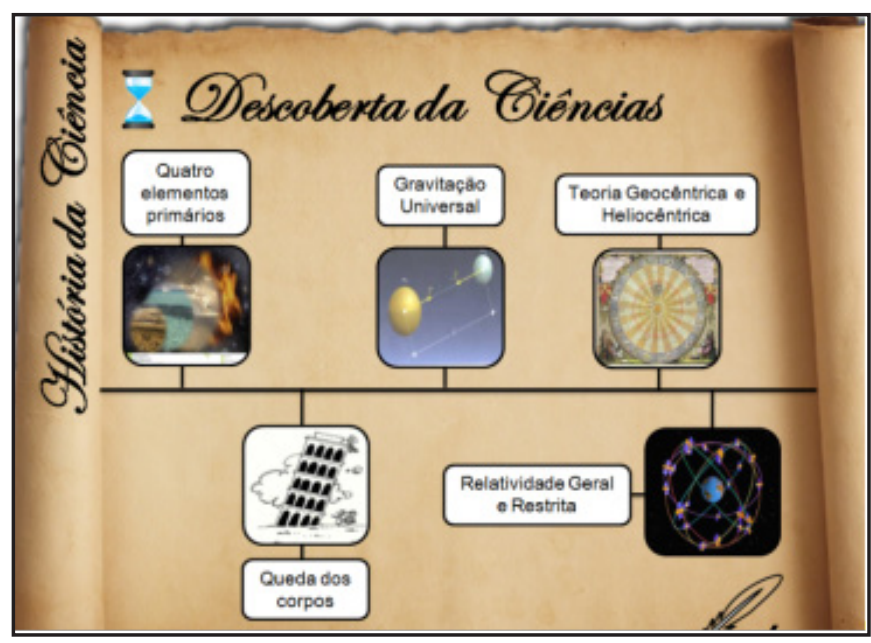

utilizados vão desde texto, links para vídeos, atividades experimentais, simulações, entre outras.

Os demais temas apresentados nesse hipertexto seguem o mesmo layout e procuram incluir os mesmos recursos didáticos para a discussão sobre o tema. Sobre o tema "Os quatro elementos primários", a proposta foi

Figura 3 - Atividades sobre Relatividade Geral e Restrita

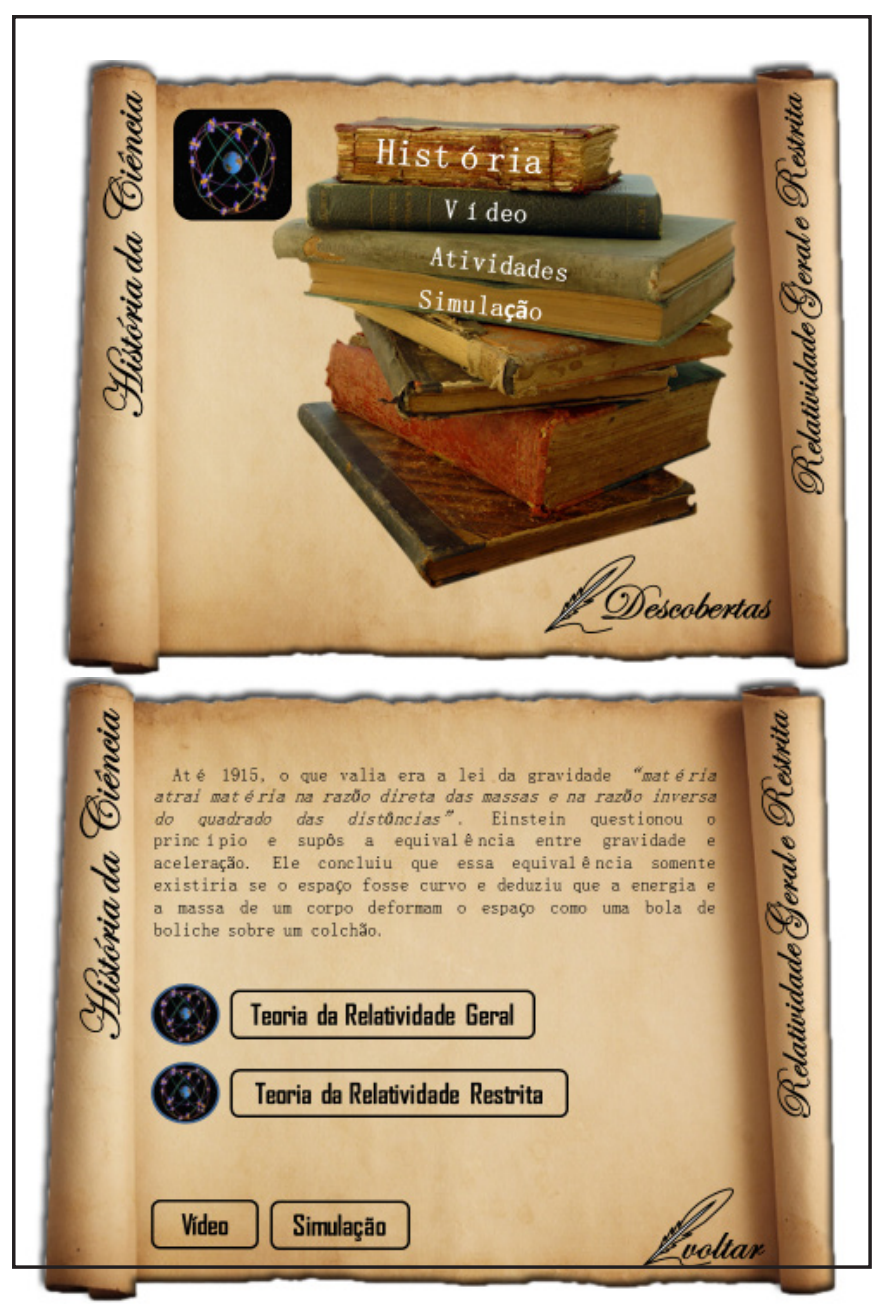


desenvolver uma atividade experimental. A partir dela foi possível verificar uma breve história sobre o tema, visto que para sobrevivência humana era necessária para o homem conhecer o mundo natural e controlar e reproduzir as forças da natureza em seu benefício.

No tema Gravitação Universal além de uma breve história são propostas inúmeras atividades, como: atividades experimentais, simulações, links para vídeos. Sobre a Teoria Geocêntrica e Heliocêntrica as ferramentas inseridas são simulações, vídeos, realização de uma História em Quadrinhos (HQ), para compreender: a ordenação do sistema solar, os movimentos de rotação e translação, o dia e a noite e nossas estações do ano. Sobre a Queda dos corpos teremos uma breve história, atividade experimental, simulação e vídeo, tornando a abordagem do assunto dinâmica, bem como verificar que é importante trabalhar este assunto em nível da Educação Básica, pois os movimentos observados na natureza sofrem resistência do meio onde ocorrem, e que todo corpo na natureza existe um lugar natural.

O hipertexto também possui a interligação entre eventos, personagens, conceitos e fatos científicos, tornando-os mais contextualizados e permitindo uma visão mais ampla dos fatos. Na tela "Biografias" (Figura 04) os estudantes conhecem breves biografias dos cientistas escolhidos para a elaboração desse trabalho.

Para navegar nessa tela o estudante pode clicar sobre a imagem do cientista e esta o levará (Figura 05) a fazer contato com textos, links, vídeos, etc., implicando em descobertas, escolhas, pistas, associação e seleção de informações, uma busca de opiniões e caminhos. Desse modo o estudante pode ter contato com a História da Ciência, mesmo que de forma simplificada.

Os conceitos explicitados no hipertexto tiveram como base os Livros didáticos indicados pelo PNLD.

Figura 4- Biografias de alguns cientistas

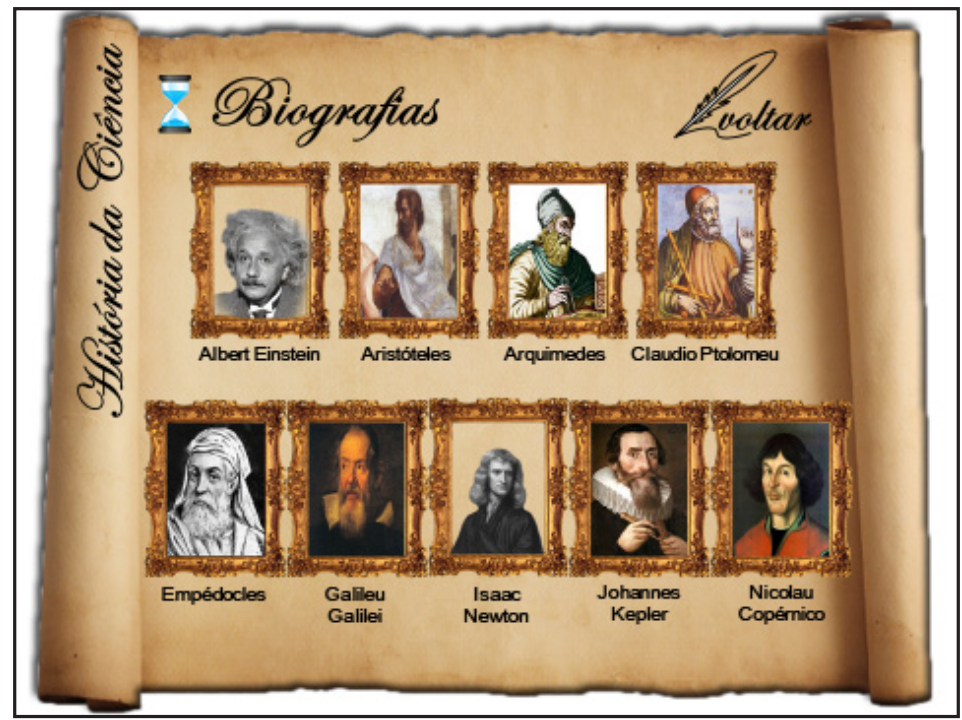

Figura 5 - Biografia de Galileu Galilei

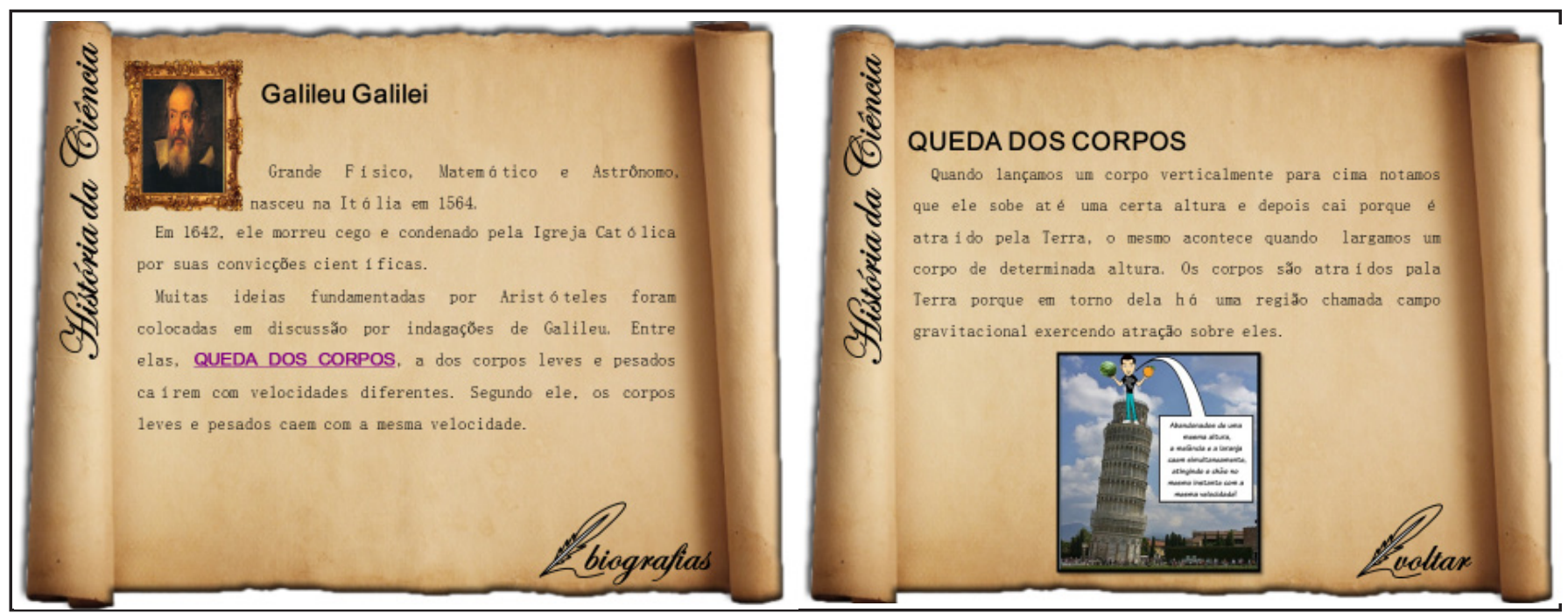




\section{Resultados e Discussões}

No primeiro encontro presencial verificou-se dificuldades de alguns estudantes em manusear o hipertexto porque não tinham domínio da tecnologia e não estavam habituados à utilização desse recurso como uma ferramenta de ensino, nem em aulas presenciais nem a distância.

Ao serem questionados sobre seus conhecimentos acerca da queda dos corpos, por meio das seguintes indagações: O que acontece se soltarmos uma pedra de uma certa altura? Por que quando soltamos ela cai em vez de subir? Por que as pessoas que estão do outro lado da Terra não caem? Por que uma pedra e um pedaço de papel, quando soltos de uma mesma altura e num mesmo momento, não chegam juntos ao chão? Os estudantes, responderam via fórum, que: a) terá uma queda livre até o solo (83\%), b) devido a força gravitacional (17\%). Diante dessas respostas pôde-se verificar que os participantes possuem conhecimento sobre o assunto, pois incluem em suas respostas conhecimentos sobre conceitos estudados em Física como: queda livre e força gravitacional.

No segundo encontro presencial foi possível verificar um grande interesse do grupo envolvido em relação ao uso das TIC em espaços presenciais e extraclasse. $\mathrm{O}$ manuseio com o Hipertexto e as diversas imagens ali apresentadas possibilitou a compreensão do tema de modo a que os estudantes produzissem desenhos tais como o apresentado na Figura 06.

\section{Figura 06- Representação do Sistema Solar realizada} por um aluno

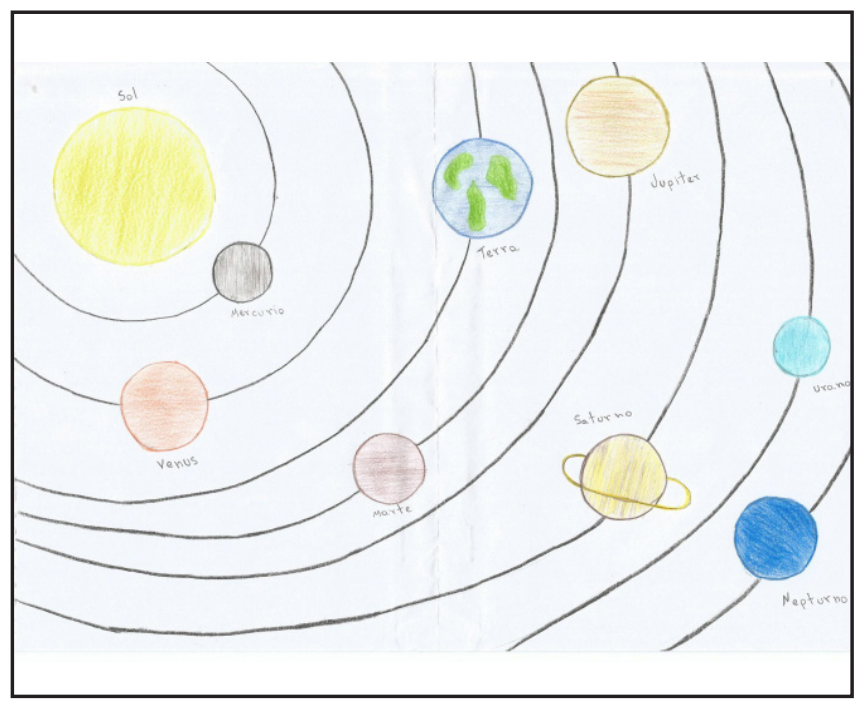

Como terceiro encontro as atividades foram desenvolvidas na modalidade a distância. As atividades referiam-se à realização de uma atividade experimental, mediante um roteiro disponibilizado no Moodle e posterior postagem e socialização do relatório da mesma no fórum, do Moodle.

No quarto encontro, realizado de forma presencial, os estudantes deveriam elaborar uma cronologia, apresentando destaques da biografia de Albert Einstein e postá-la no fórum sobre Teoria da Relatividade. Eles pesquisaram sobre a vida do cientista, suas ideias, trabalhos, vida pessoal, personalidade, etc. e leram um texto sobre sua história de vida, disponibilizado no Moodle. Alguns participantes não tinham habilidade com as TIC, por isso elaboraram cartazes, que foram entregues para a professora. Outros elaboraram um hipertexto com imagens, vídeos, links, etc. e disponibilizaram o arquivo no fórum, o que possibilitou discussões e novas aprendizagens para todos os participantes.

Ao longo de todo o trabalho, após o primeiro encontro, verificou-se que os participantes da pesquisa acessaram o Moodle em diversos horários que não apenas os das aulas presenciais. Os mesmos demonstraram interesse em ampliar o estudo sobre a construção do hipertexto sobre HC e também em construir hipertextos sobre outros temas e incluí-los em seus planejamentos didáticos, bem como em utilizar TIC na elaboração de suas aulas.

Quando indagados a respeito da recomendação das aulas para outros professores, nos moldes das atividades de aprendizagem realizadas neste trabalho, $82 \%$ deles responderam de forma afirmativa, justificando que o formato das aulas e das atividades de aprendizagem, são inovadoras, interativas e que possibilitam uma participação maior dos estudantes.

\section{Considerações Finais}

O hipertexto aqui apresentado de modo algum está completo quanto ao tema $\mathrm{HC}$, mas tinha por objetivo aliar o uso das TIC no ensino de Física e estimular o estudo e ensino do tema HC.

Durante a realização das atividades com o hipertexto, pôde-se verificar que os participantes aprovaram o uso do hipertexto para o estudo da $\mathrm{HC}$, visto que alguns tópicos estudados como: gravitação, queda dos corpos e teoria da relatividade, são temas que os estudantes possuem dificuldades em interpretar os fenômenos envolvidos, dado o número reduzido de experimentos realizáveis nos laboratórios ou demonstráveis, que podem auxiliar na compreensão, além da falta de hábitos em observar a natureza que os cercam. Os participantes consideram que a utilização de HC durante as aulas de Física permite mostrar aos estudantes o contexto social, econômico, político e social, em que viviam os cientistas durante seus estudos e descobertas, mostrando as dificuldades, erros e acertos presentes nos estudos.

O hipertexto foi considerado pelos participantes como um recurso didático importante, pois apesar de sua construção ser desafiadora, para muitos, é um recurso motivador, mediador, articulador e integrador no processo de construção do conhecimento científico. Além disso, permite que professores e estudantes sejam autores de seus próprios materiais didáticos, além de tornar mais acessível o conhecimento dado que esse recurso pode ser acessado em qualquer tempo e espaço.

Como resultado deste trabalho, espera-se que os estudantes do Parfor, participantes desta pesquisa, ampliem o tema $\mathrm{HC}$ e construam seus próprios hipertextos para o trabalho com seus estudantes da Educação Básica. 


\section{Referências}

BATISTA, I. L.; ARAMAN, E. M. de O. Uma abordagem histórico-pedagógica para o ensino de Ciências nas séries iniciais do Ensino Fundamental. Revista Electrónica de Enseñanza de las Ciencias, 2009. v.8, n. $2,466-489$.

BOETTCHER, D. M. Leitura hipertextual e aprendizagem de língua estrangeira. Signo, Santa Cruz do Sul, [Internet]. 2009 [acesso em 2014 set 12]; 34(56): 99-111. Disponível em: http://online.unisc.br/seer/index.php/signo/article/ viewFile/965/688.

BULEGON, A. M. Contribuições dos objetos de aprendizagem, no ensino de Física, para o desenvolvimento do pensamento crítico e da aprendizagem significativa. 2011. Tese de Doutorado (Informática na Educação) - Universidade Federal do Estado do Rio Grande do Sul. Disponível em: https://lume. ufrgs.br/handle/10183/39666

BULEGON, A. M.; DRESCHER, C. F.; SANTOS, L. R. Infográficos: possibilidades de atividades de ensino para aulas de Física e Química. In.: Anais ... XI ENPEC - XI Encontro Nacional de Pesquisa em Educação em Ciências. 2017. ABRAPEC: UFSC, Florianópolis/SC. [Internet]. 2017 [acesso em 2094 jun 12] Disponível em: http://www. abrapecnet.org.br/enpec/xi-enpec/anais/trabalhos.htm

BRASIL. Secretaria de Educação Média e Tecnológica. PCN + Ensino Médio: orientações complementares aos Parâmetros Curriculares Nacionais. 2002. Brasília: MEC; SEMTEC.

CAStro, R. S.; CARVAlHO, A. M. P. História da Ciência: investigando como usá-la num curso de segundo grau. Caderno Catarinense de Ensino de Física. 1992. Florianópolis. 9(3): 225-237.

DELIZOICOV, D.; ANGOTTI, J. A.; PERNAMBUCO, M. M. Ensino de Ciências: fundamentos e métodos. 2002. São Paulo: Cortez.

DESSBESELL, L. D.; FRUET, O. S. F. O potencial do hipertexto para o ensino e aprendizagem da literatura. Temporis [ação]. 2012. 12(1): 40-59.

GIL, A. C. Métodos e técnicas de pesquisa social. 1999. 5. ed. São Paulo: Atlas.

GONÇALVES, L. J., VEIT, E. A., SILVEIRA, F. L. Textos, animações e vídeos para o ensino-aprendizagem de Física térmica no Ensino Médio. Instituto de Física - UFRGS. Primeiro Encontro Estadual de Ensino de Física. 2005. Porto Alegre. Disponível em: http://www.if.ufrgs.br/mpef/ ieeefis/Atas_IEEEFIS.pdf
GUERRA, A; REIS, J. C; BRAGA, M. Um julgamento no Ensino Médio - Uma estratégia para trabalhar a ciência sob enfoque Histórico-Filosófico. Física na Escola. 2002. 3(1): 08-11.

LÉVY, P. Cibercultura. Trad. de Carlos Irineu da Costa. 1999. São Paulo: Editora.

MEdeiros, A; MEdeIROS, C. F. de. Possibilidades e Limitações das Simulações Computacionais no Ensino da Física. Revista Brasileira de Ensino de Física, 2002. 24(2): 77-86.

MENEZES, A. P. S. História da física aliada às tecnologias de informação e comunicação: Organizador Prévio como uma Estratégia Facilitadora da Aprendizagem Significativa de Física na Educação Básica.2009. Dissertação de Mestrado (Ensino de Ciências) - Universidade do Estado do Amazonas.

MINAYO, M. C. de S. O desafio conhecimento: pesquisa qualitativa em saúde. 2. ed. São Paulo: Hucitec, 1993.

NEVES, M. C. D. Einstein - Uma luz sobre a luz. [Internet]. 2006 [acesso em 2018 jan 15]. Disponível em: http://www. Física.cdcc.sc.usp.br/Professores/Einstein/

OLIVEIRA, R. A. de; SILVA, A. P. B. da. História da Ciência e Ensino de Física: Uma análise meta-historiográfica. Revista Produção on-line. Natal-RN: EDUFRN. [Internet]. 2012 [acesso em 2015 jan 12]. Disponível em: http:// ppgect.ufsc.br/files/2012/11/Temas-de-Historia-e-Filosofiada-Ciencia-no-Ensino1.pdf

PIETROCOLA, M. (Org.). Ensino de Física: conteúdo, metodologia e epistemologia em uma concepção integradora. 2005. Florianópolis: UFSC.

ROSA, P.R. da S. O uso de computadores no Ensino de Física. Parte I: Potencialidades e Uso Real. Revista Brasileira de Ensino de Física, São Paulo. 1995. 17(2):182195.

SLONGO, I. I. P. História da Ciência e Ensino de Ciências. Uma articulação possível e necessária. Revista Pedagógica. 1998. 51-74.

TORNAGHI, A. Escola faz tecnologia, tecnologia faz escola. Rio de Janeiro: COPPE/UFRJ, [Internet]. 2008 [acesso em 2014 set 11]. Disponível em: http://portal.mec. gov.br/arquivos/conferencia/documentos/tornaghi_coneb.pdf 